\title{
Reprint of: Rationale and results of the Stanford modification of the David $V$ reimplantation technique for valve-sparing aortic root replacement*
}

\author{
D. Craig Miller, MD
}

See related commentary on pages S20-1.

Even though the concept of valve-sparing aortic root replacement was introduced 35 years ago, confusion still exists about the strengths and weaknesses of the different surgical procedures used when relatively normal aortic cusps call for replacing the aortic root and preserving the regurgitant aortic valve rather than replacing the valve with a composite valve graft.

Valve-sparing aortic root replacement operations are subdivided into 2 general families: (1) the Yacoub "remodeling" technique used since $1979^{1}$ and (2) the David "reimplantation" technique performed since $1988 .{ }^{2}$ Innumerable individual modifications of the David reimplantation procedure have been described, but many surgeons are still unclear about the rationale behind these different approaches and what they strive to accomplish. At the base, all reimplantation methods firmly anchor the aortic graft proximally at the ventriculoaortic junction below the leaflets in the left ventricular outflow tract with the commissures sewn inside the polyester fabric graft. This is unphysiologic because it abolishes the pronounced 3-dimensional dynamic motion of the normal aortic annulus, but the annulus cannot dilate postoperatively, causing recurrent aortic regurgitation (AR). To Tirone David's chagrin, in 2003 I attempted to track the evolution of his personal surgical valve-sparing techniques. ${ }^{3}$ The "David I" is the original reimplantation procedure, which uses a 26- to 30-mm cylindrical tube graft. The "David II" and "David III" are variations of Yacoub's remodeling procedure (the David III incorporated a strip of polytetrafluoroethylene felt

DOI of original article: http://dx.doi.org/10.1016/j.jtcvs.2014.08.077

* This article is a reprint of a previously published article. For citation purposes, please use the original publication details; J Thorac Cardiovasc Surg. 2015;149:112-4

From the Department of Cardiovascular Surgery, Stanford University Medical School, Falk CV Research Center, Stanford, Calif.

Disclosures: Author has nothing to disclose with regard to commercial support.

Read at The American Association for Thoracic Surgery Aortic Symposium, New York, New York, April 24-25, 2014.

Received for publication Aug 11, 2014; accepted for publication Aug 20, 2014.

Address for reprints: D. Craig Miller, MD, Department of Cardiovascular Surgery, Stanford University Medical School, FALK CV Research Center, Stanford, CA 94305 (E-mail: dcm@stanford.edu).

J Thorac Cardiovasc Surg 2015;149:S18-20

0022-5223/\$36.00

Copyright (c) 2015 by The American Association for Thoracic Surgery

http://dx.doi.org/10.1016/j.jtcvs.2014.12.038 externally across the base of the noncoronary sinus from trigone to trigone of the mitral valve to minimize subsequent annular dilatation). The "David IV" is reimplantation with a 4-mm larger graft size with graft plication at the sinotubular junction above the tops of the commissures. The "David V" (used by David and me at Stanford since May 2001) uses an even larger graft size (6-8 mm bigger than that predicted by the Feindel-David formula), which is "necked down" at both the bottom and the top ends to create graft pseudosinuses. The theoretic arguments favoring polyester fabric pseudosinuses include slower aortic cusp closing velocities, which reduce the diastolic stresses on the cusps and thus potentially enhance valve durability. Despite in vivo proof of slower cusp closing velocities in human beings by Leyh and associates, ${ }^{4}$ by De Paulis and coworkers, ${ }^{5}$ and by Aybek and colleagues, ${ }^{6}$ no concrete clinical evidence exists to date to support this hypothesis of longer valve durability.

Beginning in December 2002, the Stanford group simplified the David V procedure further by using 2 separate grafts. ${ }^{7}$ A very large graft is used proximally for the pseudosinuses; this is "necked down" on the back table with 2 to 3 5-0 AT-1 Tevdek (Teleflex Medical, Research Triangle Park, NC) plication sutures in all 3 commissures to fix the annulus at a preset diameter before tying the bottom row of sutures (thereby not relying on the sutures tied tightly over a Hegar dilator to reduce the annular diameter). The bottom suture line consists of 10 to 12 horizontal mattress sutures, which are tied loosely because the diameter of the proximal end of the graft has already been made smaller. This step is the key distinction between our technique and the multitude of other methods, We downsize the big graft before we suture it loosely to the ventriculoaortic junction. In patients with a regurgitant aortic valve or bicuspid aortic valve (BAV), where the annulus is markedly dilated and there is inadequate cusp coaptation height (associated with El Khoury type I AR leak), the annulus is made substantially smaller; if the annulus is not dilated, care must be taken to not perturb its natural geometry and thus end up with a neoannulus that is too small, which can create AR, stenosis, or both. Measured on post-cardiopulmonary bypass transesophageal echocardiography, the left ventricular outflow tract or aortic annulus diameter will usually be about $5 \mathrm{~mm}$ smaller than the diameter to which the proximal graft was initially necked down, which is the distance between the inside and the outside of the aortic root. After their angular positions and height have been determined, the commissures are then 


\section{Abbreviations and Acronyms \\ $\mathrm{AR}=$ aortic regurgitation \\ $\mathrm{BAV}=$ bicuspid aortic valve \\ $\mathrm{TAV}=$ trileaflet aortic valve}

anchored in the graft while on firm stretch with 4-0 RB1 Prolene (Ethicon, Inc, Somerville, NJ); occasionally a 5-0 C1 Prolene suture is used for reimplantation when the sinus tissue rim is exceptionally friable or fragile, such as in LoeysDietz syndrome or some cases of Marfan syndrome. The large graft is then amputated at the top of the commissures, allowing ample visualization of the cusps and commissures during the valve reimplantation stage without working down inside a long, narrow-caliber graft or "chimney." When preexistent cusp prolapse and AR are present (El Khoury type II AR leak) or when making a very large annulus smaller has created cusp prolapse, the free margins of the offending cusps are shortened with 5-0, 6-0, or 7-0 GORE-TEX sutures (W. L. Gore \& Associates, Inc, Flagstaff, Ariz) in an interrupted manner starting at the nodulus of Aranti. We do not favor cusp plication extending from the free margin to the hinge or cusp excision, because this restricts systolic cusp motion and creates "doming." A second, smaller graft matching the neoannular diameter on a 1:1 ratio is then sewn to the distal ascending aorta, usually with 4-0 BB or 5-0 C1 Prolene suture. Finally, the 2 grafts are sewn together with 3-0 RB1 Prolene suture, thereby recreating the sinotubular junction. The difference in graft sizes is usually 10 to 12 $\mathrm{mm}$, and most of the graft-to-graft suture line "cheating" is achieved near the commissures, above the area where the large graft was pleated originally. Care must be exercised to avoid leaving the lesser curvature of the distal graft excessively long, which can buckle the aortic reconstruction. It also is important to avoid beveling the small distal graft to fit the large graft before the graft-to-graft anastomosis, because this defeats the purpose of recreating a circular sinotubular junction that is the same size as the neoaortic annulus. This "David V Stanford modification" technique allows the surgeon unlimited flexibility to customize the reconstruction to conform to each patient's individual pathoanatomy, including the diameter of the neoannulus, the size of the bulging pseudosinuses, the diameter of the sinotubular junction, and the heights of the pseudosinuses and commissures. This approach also provides several practical advantages, as listed, that make the procedure easier and more reproducible.

Since July 1993, a total of 331 patients have undergone a David valve-sparing aortic root replacement at Stanford; 284 of these received a David V Stanford modification. Two hundred thirty-five of the 320 patients, or $71 \%$, had trileaflet aortic valves (TAVs), and $96(29 \%)$ had BAVs; interestingly, $27 \%$ of the BAV group had a Sievers type 0 "naturally perfect" BAV with 2 commissures, 2 sinuses, and 2 symmetric cusps. Our bias is that these Sievers type 0 BAV's will prove to be more durable, but this is only conjecture at this point. One hundred twenty-seven (38\%) had Marfan syndrome, and 12 had Loeys-Dietz syndrome. Overall operative mortality was $0.6 \%$ (95\% confidence interval, $-0.2 \%$ to $1.40 \%$ ).

The 5- and 10-year results of our initial 233 patients (19932009) were reported by Kvitting and coworkers ${ }^{8}$ in 2013. Average age for the TAV cohort was $36 \pm 13$ years, versus $43 \pm 12$ years for those with a BAV. Mean follow-up interval was $4.7 \pm 3.3$ years (maximum of 15.1 years), median follow-up was 4.2 years (interquartile range, 2.3-6.6 years), and cumulative follow-up totaled 1102 patient-years. Adequate numbers of patients remained at risk to estimate with reasonable certainty 5- to 6-year outcomes for the patients with, BAV and 9- to 10-year outcomes for the patients with TAV. Survival to 10 years was superimposable on that for an age and sex-matched US population; there was no difference in survival between those with Marfan syndrome or Loeys-Dietz syndrome and those without any connective tissue disorder, nor between the BAV and TAV cohorts. ${ }^{8}$ At 10 years, freedom from reoperation on the aortic root was $92 \%$ $\pm 4 \%$ ( $\pm 1 \mathrm{SE}$ ), and freedom from structural valve deterioration was $96 \% \pm 2 \% .{ }^{8}$ Of the 6 reoperations, only 3 were aortic valve replacements. Although no significant differences in reoperation or structural valve deterioration rates were apparent between the BAV and TAV cohorts, it is not realistic to expect the BAVs to function satisfactorily as long as the normal TAVs. We preserve BAVs only if the cusps are in good condition without moderate fibrosis or calcification, because our goal in treating these young patients is to provide at least 10 if not 20 years of satisfactory valve function before the BAV ineluctably becomes stenotic and reoperation is required. For similar reasons, we do not favor preserving BAVs in older patients because we have reasonable alternative options that are less complex and more durable.

The longest follow-up of patients after valve-sparing aortic root replacement with the reimplantation technique is David's personal series of 296 patients. ${ }^{9}$ Average age was 45 years. Mean follow-up was $6.9 \pm 4.5$ years; however, only 21 patients remained at risk after 15 years. Operative mortality rate was $1 \%$. At 15 years, survival was $77 \% \pm 18 \%$, freedom from reoperation on the aortic valve was $98 \% \pm 5.3 \%$, and freedom from moderate or severe AR was $90 \% \pm 12 \%$.

Our Stanford results ${ }^{8}$ and David's results ${ }^{9}$ satisfy the surgical quality standards laid out by Reed Pyeritz and others for the National Marfan Foundation, stating that valvesparing aortic root replacement should only be performed in centers where the operative mortality is less than $1 \%$ and the 10-year freedom from valve reoperation exceeds 
$90 \%$. Whether these results are generalizable can only be answered by multi-institutional, prospective investigations such as the 19-center Aortic Valve Operative Outcomes in Marfan Patients registry sponsored by the National Marfan Foundation, ${ }^{10}$ which will continue to 2021 when each patient has been followed up for a minimum of 10 years. This knowledge is essential if we are to learn where valvesparing aortic root replacement fits in our armamentarium, who should do it, and where it should be performed. Certainly this is one procedure that should not be done in low-volume institutions on an episodic basis. The surgical learning curve is too steep, and too unforgiving.

It is important to remind ourselves that the 15- to 20-year durability of these procedures, the reoperative mortality risk for the obligate failures, and whether the cumulative valve-related morbidity and mortality risk is lower than that of receiving a composite valve graft with a mechanical prosthesis still remain unknown. We should know this information in another 10 years.

\section{References \\ 1. Yacoub M, Fagan A, Stassano P, Radley-Smith R. Results of valve conserving operations for aortic regurgitation [abstract]. Circulation. 1983; 68(Suppl):III321.}

2. David TE, Feindel CM. An aortic valve-sparing operation for patients with aortic incompetence and aneurysm of the ascending aorta. J Thorac Cardiovasc Surg. 1992;103:617-21; discussion 622.

3. Miller DC. Valve-sparing aortic root replacement in patients with the Marfan syndrome. J Thorac Cardiovasc Surg. 2003;125:773-8.

4. Leyh RG, Schmidtke C, Sievers HH, Yacoub MH. Opening and closing characteristics of the aortic valve after different types of valve-preserving surgery. Circulation. 1999;100:2153-60.

5. De Paulis R, De Matteis GM, Nardi P, Scaffa R, Bassano C, Chiariello L. Analysis of valve motion after the reimplantation type of valve-sparing procedure (David I) with a new aortic root conduit. Ann Thorac Surg. 2002; 74:53-7.

6. Aybek T, Sotiriou M, Wöhleke T, Miskovic A, Simon A, Doss M, et al. Valve opening and closing dynamics after different aortic valve-sparing operations. J Heart Valve Dis. 2005;14:114-20.

7. Demers P, Miller DC. Simple modification of "T. David-V" valve-sparing aortic root replacement to create graft pseudosinuses. Ann Thorac Surg. 2004;78: 1479-81.

8. Kvitting JP, Kari F, Fischbein MP, Liang DH, Beraud AS, Stephens EH, et al. David valve-sparing aortic root replacement: equivalent mid-term outcome for different valve types with or without connective tissue disorder. J Thorac Cardiovasc Surg. 2013;145:117-26. 127.e1-5; discussion 126-7.

9. David TE, Armstrong S, Manlhiot C, McCrindle BW, Feindel CM. Long-term results of aortic root repair using the reimplantation technique. J Thorac Cardiovasc Surg. 2013;145(3 Suppl):S22-5.

10. Coselli JS, Volguina IV, LeMaire SA, Sundt TM, Connolly HM, Stephens EH, et al; Aortic Valve Operative Outcomes in Marfan Patients Study Group. Early and 1-year outcomes of aortic root surgery in patients with Marfan syndrome: a prospective, multicenter, comparative study. J Thorac Cardiovasc Surg. 2014; 147:1758-66. 1767.e1-47.

\title{
EDITORIAL COMMENTARY
}

\section{Reprint of: Valve-sparing aortic root replacement: Too many cooks?*}

\author{
John S. Ikonomidis, MD, PhD
}

See related article on pages S18-20.

According to the Society of Thoracic Surgeons database, approximately $11 \%$ of patients who underwent aortic root replacement between January 2000 and June 2011 received a valve-sparing procedure. Valve-sparing aortic root

DOI of original article: http://dx.doi.org/10.1016/j.jtcvs.2014.11.020

* This article is a reprint of a previously published article. For citation purposes, please use the original publication details; J Thorac Cardiovasc Surg. 2015;149:114-5.

From the Division of Cardiothoracic Surgery, Medical University of South Carolina, Charleston, SC.

Disclosures: Author has nothing to disclose with regard to commercial support.

Received for publication Nov 12, 2014; accepted for publication Nov 13, 2014.

Address for reprints: John S. Ikonomidis, MD, PhD, Division of Cardiothoracic Surgery, Suite 7030, 25 Courtenay Dr, Charleston, SC 29425 (E-mail: ikonomij@musc.edu).

J Thorac Cardiovasc Surg 2015;149:S20-1

$0022-5223 / \$ 36.00$

Copyright (c) 2015 by The American Association for Thoracic Surgery

http://dx.doi.org/10.1016/j.jtcvs.2014.12.034 replacement has become a well-established option for patients with aortic root aneurysms who have morphologically normal tricuspid or noncalcified, pliable bicuspid aortic valves. The procedure carries obvious advantages for young patients in that it avoids the need for a mechanical-valved conduit and the concomitant requirement for long-term anticoagulation.

Since the original descriptions of valve-sparing aortic root replacement by Sir Magdi Yacoub and Dr Tirone David, we have learned much about the characteristics of this procedure. Perhaps the most important thing that we learned relatively early on was that the reimplantation procedure was superior to the remodeling procedure because of its stabilization of the annulus. Since this discovery, numerous iterations of the reimplantation operation have been suggested and performed.

In this issue of the Journal, Dr Miller ${ }^{1}$ provides an excellent and concise summary of the history and development of the valve-sparing aortic root replacement, with specific attention to the various iterations of the David 